Document downloaded from:

http://hdl.handle.net/10251/122859

This paper must be cited as:

Certa, A.; Enea, M.; Galante, G.; Izquierdo Sebastián, J.; La Fata, CM. (2018). Food safety risk analysis from the producers' perspective: prioritisation of production process stages by HACCP and TOPSIS. International Journal of Management and Decision Making. 17(4):396414. https://doi.org/10.1504/IJMDM.2018.095720

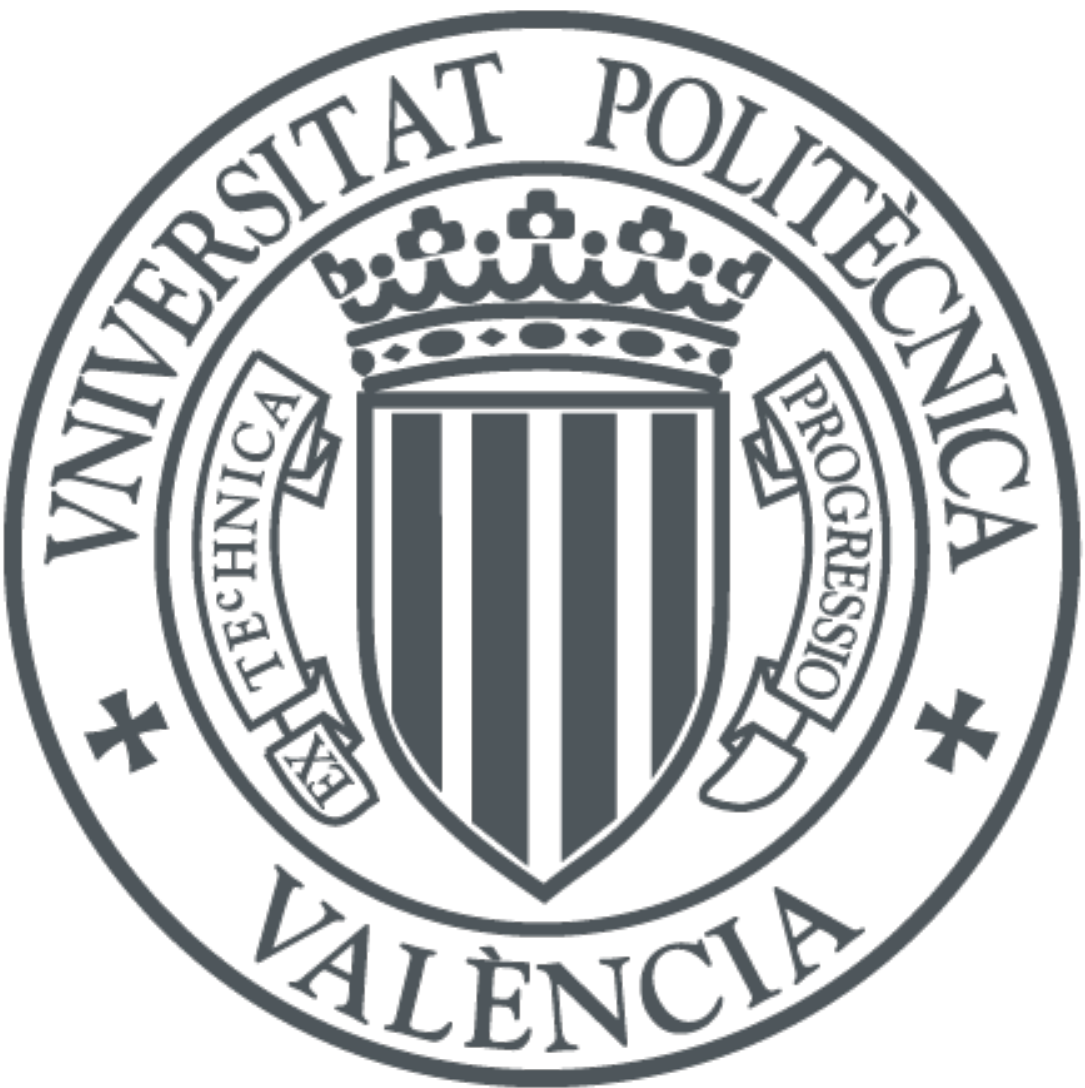

The final publication is available at

http://doi.org/10.1504/IJMDM.2018.095720

Copyright Inderscience Enterprises Ltd.

Additional Information 


\section{Food safety risk analysis from the producers' perspective: prioritization of production process stages by HACCP and TOPSIS}

Certa A.*, Enea M.*, Galante G.M.*, Izquierdo J.**, La Fata C.M.*

* Dipartimento dell'Innovazione Industriale e Digitale (DIID) Ingegneria Chimica, Gestionale, Informatica, Meccanica, Università degli Studi di Palermo, Viale delle Scienze, bld.8, 90128 - Palermo - Italy (antonella.certa@unipa.it,mario.enea@unipa.it, giacomomaria.galante@unipa.it, concettamanuela.lafata@unipa.it)

** FluIng, Instituto Universitario de Matemática Multidisciplinar, Universitat Politècnica de València, Camino de Vera s/n, bld.8G, 46002- Valencia - Spain (jizquier@upv.es)

Antonella Certa received a Master Degree in Management Engineering in 2004, and a Ph.D. in Economic Analysis, Technology Innovation and Management of the Development Policy Studies Program in 2008 at the University of Palermo. She currently is professor of Industrial Plants at the University of Palermo. Prof. Certa's research interests are mainly focused on project management, multi-criteria analysis and maintenance optimization models.

Mario Enea is full professor of Project Management, Industrial Plants Management and Applied Economics for Engineering at the University of Palermo. His research fields include production management, scheduling problems related to project management, optimal layout problems, environmental impact evaluation and waste management.

Giacomo Maria Galante is full Professor of Industrial Plants at the University of Palermo. His present research fields are mainly focused on industrial plant layout optimization, reliability and maintenance policies, risk analysis, and project management. He has been scientific manager of several projects of applied research, particularly in the field of the maintenance optimization and risk analysis, financed by the Italian Government and by other public and private organizations.

Joaquín Izquierdo PhD in Mathematics, full professor of Applied Mathematics. Educational career developed in the Universitat Politècnica de València (Spain), teaching Algebra, Calculus, Differential Equations, Numerical Methods applied to Engineering, etc. Research activity in knowledge-based systems and DSSs in Engineering (mainly Urban Hydraulics). Author and editor 
of books, research papers, and contributions to international events. Tutor of several doctoral dissertations. Consulting in water resources. Continuous professional development for Spanish and Latin-American professionals. Author of commercial computer simulation packages. Co-organizer of periodically international events. Participation in R\&D projects at local, regional, national, European, and international levels.

Concetta Manuela La Fata is postdoc at the University of Palermo. She holds a Master Degree in Management Engineering and a Ph.D. in Technique and Economy of Transport at the University of Palermo. Her research has been focused on risk analysis in major hazard plants and calculation of reliability/availability of complex systems; methods to deal with the epistemic uncertainty; maintenance optimization modeling; mathematical programming modeling with particular attention to routing and scheduling problems. 


\title{
Food safety risk analysis from the producers' perspective: prioritization of production process stages by HACCP and TOPSIS
}

\begin{abstract}
From the manufacturers perspective, the Hazard Analysis and Critical Control Point (HACCP) system nowadays represents the mainly way to implement the food safety risk management in food industries. Nevertheless, the identification and prioritization of hazards as the outcome of the first principle of HACCP is not sufficient to identify production process stages that more significantly and critically contribute to the consumer's risks. With this recognition, the present paper proposes a Quantitative Risk Assessment (QRA) approach based on HACCP and Technique for Order of Preference by Similarity to Ideal Solution (TOPSIS) to individuate production process phases on which implementing corrective actions to improve the consumers' safety. The designed methodological approach is implemented on the smoked salmon manufacturing process of a real Sicilian industry.
\end{abstract}

Keywords: Analysis of production process stages; Food safety risk analysis; HACCP; TOPSIS. 


\section{Introduction}

As emphasized by the Food and Agriculture Organization of the United Nations (FAO) and the World Health Organization (WHO) (FAO/WHO, 2005), traditional food safety systems are recognized as "inadequate to cope with the complex, persistent pervasive and evolving array of food safety issues existing today". To the contrary, "modern food safety systems are to be sciencebased to effectively cope with, and respond to, the wide range of food safety challenges". Actually, science-based results may support Decision Makers (DMs) (e.g. government officials, food manufacturers and processors) to minimize the occurrence of food-borne hazards, to reduce and manage risks, and to improve the outcomes of the decision-making process.

As a concept, a science-based approach to the food safety is not completely new. What is new is the use of science-based approaches within the risk analysis framework fairly recently introduced in the food field to effectively manage, evaluate and communicate risks. Nowadays, the food safety risk analysis is more and more considered as a powerful framework on the basis of which taking science-based decisions with the aim of promoting ongoing improvements in the public health. In regard to this, the FAO and the WHO (FAO/WHO, 2005) assert that "a risk analysis framework provides a process to systematically and transparently collect, analyze and evaluate relevant scientific and non-scientific information about a chemical, biological or physical hazard possibly associated with food in order to select the best option to manage the risk". Therefore, the food safety risk analysis can be seen as a structured decision-making process to quantify risks caused by food-borne hazards to human health and to identify, assess and implement appropriate measures of intervention to control such risks (Butler, 2008).

According to the Regulation EC No 178/2002 (Regulation EC No 178, 2002), the food safety risk analysis consists of three highly interrelated components, namely the risk management, the risk assessment and the risk communication (FAO/WHO, 2006). Specifically, the same Regulation reports the following definitions: 
- risk assessment means a scientifically based process consisting of four steps: hazard identification, hazard characterization, exposure assessment and risk characterization;

- risk management means the process, distinct from the risk assessment, of weighing policy alternatives in consultation with interested parties, considering risk assessment and other legitimate factors and, if need be, selecting appropriate prevention and control options;

- risk communication means the interactive exchange of information and opinions throughout the risk analysis process as regards hazards and risks, risk-related factors and risk perceptions, among risk assessors, risk managers, consumers, feed and food businesses, the academic community and other interested parties, including the explanation of risk assessment findings and the basis of risk management decisions.

Generally speaking, risk management decisions can be made by different public and private stakeholders (e.g. government officials, food manufacturers and processors, and consumers). From the manufacturers' point of view, the Hazard Analysis and Critical Control Point (HACCP) system nowadays represents the mainly way to implement the food safety risk management in food industries (FAO/WHO, 2005). Worldwide implemented by food producers and processors, HACCP is a systematic approach for the identification, evaluation, and control of food safety hazards (FAO/WHO, 1997; ISO 22000, 2005; Regulation EC No 852, 2004). Among the seven principles of the HACCP plan development (National Advisory Committee for Microbiological Criteria for Foods, 1998), the first one is the hazard analysis. It comprises two stages, namely the hazard identification and the hazard evaluation. As concerns the hazard identification, it aims at developing a list of potential chemical, biological and physical hazards which may be introduced, increased, or controlled at every step of the production process under investigation. On the other hand, the hazard evaluation aims at characterizing every identified hazard by the related Occurrence $(O)$ and Severity (S) parameters. Specifically, O stands for the probability/frequency of occurrence of the hazard whereas S represents the level of damage as a consequence of the hazard's occurrence. Therefore, 
the hazard analysis refers to the process of collecting and evaluating information on hazards associated with the food under consideration to look at the conditions that may cause hazards to be present or to increase, and to decide which hazards must be addressed into the HACCP plan (Oscar, 2012). Actually, listed hazards are so numerous that none food safety system can address all related potential problems. As a consequence, key part of risk management involves ranking hazards for risk assessment, and setting priorities for risk management to enable informed decision-making and resource allocation (FAO/WHO, 2005; Jain et al., 2017). However, none specification is supplied by the technical literature as concerns the way how collection and evaluation of hazards' information need to be performed (Oyarzabal, 2015), as well as none structured framework by means of which prioritizing hazards is suggested.

Apart from the prioritization of hazards to identify the ones to be addressed into the HACCP plan, one has to consider that such prioritization is not sufficient to identify the most critical production process stages on which implementing corrective measures with priority to reduce risks to consumers. The latter is particularly true when the same hazard may be introduced or increased at different process stages. Therefore, in regard to the problem of setting priorities of intervention among the different production process stages, the traditional HACCP-based approach for the identification of Critical Control Points (CCPs) could benefit of a structured Quantitative Risk Assessment (QRA) method (Bevilacqua and Ciarapica, 2018). In the authors' opinion, the application of QRA, compatible and even complementary of the traditional approach, may represent, for food producers and processors, a support tool for taking risk-informed decisions to ensure the consumers' safety by a better control of processes. In the light of that, the present paper proposes a semi-quantitative approach based on HACCP and Technique for Order of Preference by Similarity to Ideal Solution (TOPSIS) (Hwang and Yoon, 1981) to prioritize production process stages on the basis of their actual contribute to the consumers' risk. Referring to a real smoked salmon manufacturing process, the hazard analysis is firstly performed by the HACCP team of the 
involved organization. The result of the hazard analysis is a list of known or potential food-borne hazards along with the production stage wherein every hazard may occur. Afterwards, the TOPSIS method is used to rank production stages with the aim of identifying the ones of such significance to cause damages to consumers if not effectively controlled. To such prioritization aim, hazards are rated against three different evaluation criteria with relation to every production phase where hazards themselves may occur. Specifically, the frequency of Occurrence (O), the Severity (S) and the Detectability (D) of hazards are taken into consideration as evaluation criteria. Apart from $\mathrm{O}$ and S parameters previously defined, the Detectability represents the probability of the hazard to be detected by means of visual inspections or microbiological analyses performed at every manufacturing phase. In addition, evaluation criteria are properly weighted by the HACCP team to reflect the relative importance of criteria in terms of contribution to the consumers' risk.

To the best of the Authors' knowledge, the extant body of the literature on the prioritization issue in food manufacturing environments has been mainly focused on the proposal of the Failure Mode and Effects Analysis (FMEA) (IEC 60812, 2006). FMEA is a systematic and predictive procedure for the reliability analysis of complex systems/processes to identify potential failure modes, their causes and effects on the system performance. When addressed to the prioritization of failure modes, FMEA is referred to as Failure Mode, Effects and Criticality Analysis (FMECA). Within FMECA, failure modes are ranked on the basis of a metric called Risk Priority Number (RPN) that is computed as the product of parameters $\mathrm{S}, \mathrm{O}$ and $\mathrm{D}$ related to every failure mode. Despite its wide applications into different industrial fields, the use of the traditional RPN method has been criticized to have several shortcomings (Carpitella et al., 2018b; Certa et al., 2017a; Certa et al., 2017b; Liu et al., 2013) some of which are listed below.

- RPNs' parameters (i.e. O, S and D) are equally weighted.

- Different combinations of O, S, and D may produce exactly the same value of RPN, but their hidden risk implications may be totally different. 
- The mathematical formula for calculating the RPN has been debated, because there is no rationale in obtaining the RPN as the product of risk factors $\mathrm{O}, \mathrm{S}$ and $\mathrm{D}$.

Differently from the RPN-based method, the TOPSIS one here proposed allows at differently weighting criteria on the basis of the DM's perceptions. Such characteristic of TOPSIS makes able a better management of the information available on the decision-making problem to be dealt. Actually, the TOPSIS method helps the DM to better organize the problem to be solved and to carry out analyses, comparisons and ranking of alternatives in a more structured way (Kumar and Agrawal, 2009).

The remainder of the paper is organized as follows. The literature review is reported in Section 2, whereas the TOPSIS method is described in Section 3. The application case is presented in Section 4, and final conclusions are drawn in Section 5.

\section{Literature review}

So far, from the food manufacturers' perspective, food safety risk assessment and management problems have been mainly dealt by the FMEA method. However, despite its wide application in reliability and risk analyses fields (Chang et al., 2017; Sutrisno et al. 2015), the use of FMEA in the food safety context is quite recent. In (Ozilgen, 2012), FMEA is applied for the risk assessment in a small scale confectionery manufacturing company. Potential failures (i.e. food-borne hazards) and their possible causes are identified for every process stage. Afterwards, the risk level of potential failures is identified by the traditional RPN. In Scipioni et al. (2002), the FMEA methodology is integrated into the HACCP system to assure the products' quality and to improve the operational performance of the whole production cycle. From an operational point of view, the impact of every single failure on the final product quality is evaluated in terms of food safety and exterior aspects, and considering every product characteristic that can affect the customer's satisfaction. Arvanitoyannis and Varzakas $(2008 ; 2009)$ and Varzakas (2011) use FMEA for the risk assessment 
of pastry processing, snail industry and salmon processing respectively, and carry out a comparison between ISO 22000 (2005) and HACCP. Varzakas and Arvanitoyannis (2007) combine FMEA and preliminary hazard analysis together with the Fault Tree Analysis (FTA) (IEC 61025, 2006) for the risk assessment of a corn curl processing plant. Referring to two medium-size bakeries located in Poland, Trafialek and Kolanowski (2014) propose a combined HACCP and FMEA approach for the identification of high and critical risks in HACCP areas of verification and recordkeeping. One more time, Xiaochuan and Qiang (2015) refer to a meat production process to propose an integrated FMEA and HACCP approach. The latter is applied to analyze potential failure modes and to compute related RPNs. Afterwards, obtained results are used to formulate the HACCP plan of the investigated company. Kurt and Özilgen (2013) approach the criticality assessment of manufacturing processes of six widely consumed dairy products in Turkey by means of the traditional RPN method. Sixty-seven process's hazards are identified and the related RPNs computed to rank them. Referring to a company operating in the fishing sector, Carpitella et al. (2017) propose a combined HACCP and TOPSIS method approach to prioritize chemical, biological and physical food-borne hazards. Bertolini et al. (2007) combine FTA (Curcurù et al., 2013) and Fuzzy Sets Theory (FST) (La Fata and Lupo, 2017; Bevilacqua et al., 2018) to objectively and automatically implement the first and second principles of the hazard analysis in the application of HACCP, which are the identification of risk priorities and of the related CCPs. In particular, FTA is used for the analytical decomposition of the manufacturing process whereas FST is applied to quantitatively measure the occurrence parameter. In (Doménech et al., 2007), the use of QRA is introduced to estimate the risk to consumers' health and the induced company's economic losses. Authors declare that information provided by QRA could be used to prioritize safety management measures needed according to the real importance of hazards identified for a particular food processing. Doing that, a better protection of consumers' health and a more cost effective and efficient management of the food industry could be simultaneously achieved. Serra et 
al. (1999) propose an enhanced version of traditional HACCP where QRA is incorporated to estimate the risk of consequences arising from the occurrence of some production process deviations. Referring to a mineral water packaging process, the hazard analysis is firstly performed, followed by a risk quantification stage where cause-consequence analysis and FTA are respectively applied to determine possible consequences and causes of every process deviation.

Differently from the main extant body of the literature, a TOPSIS-based approach is suggested in the present paper to deal with the food safety risk assessment issue. To the best of the authors' knowledge, TOPSIS has been widely applied in diverse industrial contexts for the risk management and assessment (KarimiAzari et al., 2011; Zhang et al., 2013) but only few contributions exist as concerns its applications in the food context. Referring to a real Italian company, Grassi et al. (2009) propose a multi-criteria analysis to evaluate risks to workers involved in the execution of tasks related to a sausage production process. The fuzzy TOPSIS method is particularly suggested to obtain the final ranking of activities by introducing factors which take explicitly into account the effect of the human behavior and of the environment on risk levels. Taylan et al. (2017) propose the use of fuzzy TOPSIS to evaluate the competitiveness of some food manufacturing industries. Jędrkiewicz et al. (2018) recently propose a combined approach, based on Self-Organizing Maps (SOM) and TOPSIS, for the determination of the presence of furan in food samples. Among a set of 22 alternatives, TOPSIS is used to select the most preferable analytical procedure to estimate the presence of furan.

\section{Overview on the TOPSIS method}

The TOPSIS method was firstly proposed by Hwang and Yoon (1981) and further developed by Hwang et al. (1993) as a Multi-Criteria Decision Making (MCDM) technique by means of which ranking alternatives on the basis of their ratings against diverse qualitative and/or qualitative criteria opportunely weighted. TOPSIS has been widely applied in the literature since its ability to deal with different decision problems addressed to the ranking of alternatives (Hu et al., 2016; Carpitella et 
al., 2018a). To taxonomize the research on TOPSIS applications, an interesting study about the state of the art is proposed by Behzadian et al. (2012). Authors assert that TOPSIS continues to work satisfactorily across different application areas such as the suppliers' selection (Govidan, et al., 2013), the machine location selection (Rubayet and Karmaker, 2016), the hazardous waste transportation (Gumus, 2009), and so on (Azarnivand and Banihabib, 2017). TOPSIS may involve a single analyst (i.e. decision maker) or a group of decision makers (Awasthi et al., 2010; Certa et al., 2013; Lourenzutti and Krohling, 2016; Shih, 2008). In addition, its fuzzy extension (Chen, 2000) allows at dealing with the uncertainty and imprecision of input data (Aiello et. al, 2009; Carpitella et al., 2016; Carpitella et al., 2018b; Galante and La Fata, 2017; La Scalia et al., 2011; La Scalia et al., 2016; Lima et al., 2014; Wang et al., 2015; Zeydan et al., 2011).

TOPSIS is based on the concept of distances between every alternative and the positive (Azimuth) and negative ideal (Nadir) solutions. Therefore, the best alternative among those under investigation is the one characterized by the shortest distance from the Azimuth and the farthest distance from the Nadir. The implementation of TOPSIS consists of the following steps.

1. Collection of scores $g_{i j}$ of every alternative $i$ (with $i=1, \ldots, n$ ) against every criterion $j$ (with $j=1, \ldots, k)$. Elements $g_{i j}$ constitute the so called decision matrix.

2. Definition of the importance weight of every criterion $j$, i.e. $w_{j}$.

3. Computation of the weighted and normalized decision matrix. Let $z_{i j}$ be the rating of the alternative $i$ under the criterion $j$ normalized by the equation (1):

$$
z_{i j}=\frac{g_{i j}}{\sqrt{\sum_{i} g_{i j}^{2}}} \forall i, \forall j
$$

Then, the generic element $u_{i j}$ of the weighted and normalized matrix is computed as follows (Eq. 2):

$$
u_{i j}=w_{j} \cdot z_{i j}, \forall i, \forall j
$$


4. Identification of the positive and negative ideal solutions $A^{+}$(Eq. 3) and $A^{-}$(Eq. 4) respectively:

$$
\begin{aligned}
A^{+} & =\left\{u_{1}^{+}, \ldots, u_{k}^{+}\right\}= \\
& =\left\{\left(\max _{i} u_{i j} \mid j \in I^{\prime}\right),\left(\min _{i} u_{i j} \mid j \in I^{\prime \prime}\right)\right\} \\
A^{-} & =\left\{u_{1}^{-}, \ldots ., u_{k}^{-}\right\}= \\
& =\left\{\left(\min _{i} u_{i j} \mid j \in I^{\prime}\right),\left(\begin{array}{c}
\max _{i} u_{i j} \mid j \in I^{\prime \prime} \\
i
\end{array}\right)\right\}
\end{aligned}
$$

where $I^{\prime}$ is the set of benefit criteria, whereas $I^{\prime \prime}$ is the set of cost criteria.

5. Computation of distances $S_{i}^{+}$and $S_{i}^{-}$of every alternative $i$ from $A^{+}$(Eq. 5) and $A^{-}$(Eq. 6) respectively.

$$
\begin{aligned}
& S_{i}^{+}=\sqrt{\sum_{j}\left(u_{i j}-u_{j}^{+}\right)^{2}}, \forall i \\
& S_{i}^{-}=\sqrt{\sum_{j}\left(u_{i j}-u_{j}^{-}\right)^{2}}, \forall i
\end{aligned}
$$

6. Computation of the closeness coefficient $C_{i}$ (Eq. 7), with $0 \leq C_{i} \leq 1$.

$$
C_{i}=\frac{S_{i}^{-}}{S_{i}^{-}+S_{i}^{+}}, \forall i
$$

7. Ranking of alternatives on the basis of the obtained closeness coefficients, namely if $C_{i}>C_{m}$ then the alternative $i$ is to be preferred to the alternative $m$.

\section{Case study}

The combined HACCP and TOPSIS-based approach is here applied to the smoked salmon manufacturing process of a real Sicilian industry which has been operating in the fishing sector for 
many years. The company under consideration commercializes its products in Italy and in foreign markets both with their own brands and private labels. Its mission is to ensure high quality and safety finished products that contribute to a nutritionally balanced diet, renowned for its excellent taste and superior quality, realized drawing inspiration from traditions and from the Sicilian territory. To achieve its mission, the company pays particular attention both on the selection of raw materials and on the control of manufacturing processes. In regard to this, suppliers are from Alaska, Norway and Scotland, and a dedicated productive structure of 4,800 $\mathrm{m}^{2}$ over an area of $16,000 \mathrm{~m}^{2}$ was opened in Sicily in 2013 according to the highest standards of safety. Environmental and productive process parameters, products' specifications and rules regarding the staff are certified by the British Retail Consortium (BRC) and the International Food Standard (IFS).

The smoked salmon manufacturing process under consideration begins with the receiving of fillets of frozen salmons and ends with the distribution of finished products to consumers (Figure 1).

\begin{tabular}{|l|l|}
\hline 1. & - Fish Receiving \& Acceptance Check \\
2. & - Defrosting \\
3. & - Washing and Salting \\
4. & - Smoke Flavoring \\
5. & - Slicing \\
6. & - Packaging \& Labeling \\
7. & - Distribution \\
\hline
\end{tabular}

Figure 1 Process flow diagram

Stages of the smoked salmon manufacturing process are detailed in the following.

- Fish receiving and acceptance check: fillets of frozen salmons are delivered by suppliers by their own refrigerated trucks. At the receiving, the weight and the integrity of packages are firstly 
checked. Afterwards, a sample of frozen salmons is firstly defrosted and then sent to the laboratory for the microbiological analysis. The latter includes the post-mortem $\mathrm{pH}$ monitoring. For $\mathrm{pH}$ values higher than 7 , the whole lot is rejected and sent back to the supplier.

- Defrosting: once the received lot is accepted, fillets of salmons are defrosted into appropriate rooms where the temperature is opportunely monitored. The presence of extraneous matters is verified during this stage and salmons are then sent to the production line.

- Washing and salting: such stage is performed into a specific room which is sanitized every three hours to avoid the fish contamination by the Listeria monocytogenes bacterium. The temperature is kept beneath the $7^{\circ} \mathrm{C}$, and salmons are manually placed on steel shelves where they are visually checked to ensure the absence of residual scales and impurities due to the filleting process previously performed by suppliers. Then, fishes are washed with water and finally salted.

- Smoke flavoring: washed and salted fillets of salmons are placed on appropriate trolleys and introduced into particular ovens where the humidity and the temperature are opportunely monitored. Generally speaking, there are two types of smoke flavoring processes, namely the socalled hot smoked salmon that takes place at temperatures of about $70^{\circ} \mathrm{C}$, and the cold one which uses a temperature between $25^{\circ} \mathrm{C}$ and $30^{\circ} \mathrm{C}$. The company performs a cold smoke flavoring process which makes use of beech wood and lasts for 15-18 hours. As the hot smoked salmon process, the cold one applied on farmed fishes, together with appropriate hygienic measures, ensures safety and quality products.

- Slicing: such stage begins with the automated skin removal, and carries on with a manual removal of residual skin and fish bones. Afterwards, fillets are sent to a slicer machine which produces slices having a thickness of $1.5 \mathrm{~mm}$, and trays of different size and weight are manually prepared. 
- Packaging and labeling: salmons' trays are weighed by a specific machine and vacuum packed to avoid air bubbles and thus the development of bacteria. Packages are labeled to include information such as expiration date, lot number, etc. A further microbiological analysis is performed on samples of finished products before the distribution.

As required by the HACCP system, the organization also performs the hazard analysis of the smoked salmon manufacturing process with the aim of identifying known and potential hazards that may have an adverse effect on the human health. The main part of identified hazards is specifically regulated in order to contribute to the protection of the public health and to establish harmonized safety criteria on the acceptability of food, in particular as regards the presence of certain pathogenic micro-organisms. For instance, the Commission Regulations EC No 2073/2005 (Commission Regulation EC No 2073, 2005) and No 1881/2006 (Commission Regulation EC No 1881, 2006) are to be complied for the Listeria Monocytogenes whereas the benzopyrene is regulated by the Commission Regulation EC 835/2011 (Commission Regulation EC 835, 2011). However, the hazard analysis as the first principle of HACCP does not represent the main focus of the present paper which is instead addressed to the proposal of a semi-quantitative and structured method to prioritize the production process stages on the basis of their actual contribute to the consumers' risk. The TOPSIS method is applied to this purpose. Specifically, identified food-borne hazards are firstly assessed against the three criteria $\mathrm{O}, \mathrm{S}$ and D by means of the discrete scale [1, 10]. As concerns the parameter $\mathrm{D}$, it is ranked in a reverse order in respect to $\mathrm{S}$ and $\mathrm{O}$, namely the higher the detection value, the smaller the probability to detect the hazard. Therefore, all criteria are characterized by a decreasing versus of preference, namely $\mathrm{O}, \mathrm{S}$ and $\mathrm{D}$ are to be minimized. Chemical, physical and biological hazards identified by the HACCP team of the involved organization are synthesized in Table 1 along with the related ratings against criteria $\mathrm{O}, \mathrm{S}$ and $\mathrm{D}$ (i.e. $g_{i j}$ ). 
Table 1 Identified hazards and ratings against criteria $\mathrm{O}, \mathrm{S}$ and $\mathrm{D}$

\begin{tabular}{llllll}
\hline \multicolumn{1}{c}{$\begin{array}{c}\text { Process } \\
\text { stage }\end{array}$} & Hazard Number & \multicolumn{1}{c}{ Hazards } & O & S & D \\
\hline $\begin{array}{l}\text { Fish receiving } \\
\text { and acceptance } \\
\text { check }\end{array}$ & 1.1 & Chemical Hazards & & \\
& 1.2 & Heavy metal $(\mathrm{Hg}, \mathrm{Cd}, \mathrm{Pb})$ & 2 & 8 & 5 \\
& & Allergens & 2 & 6 & 5 \\
& 1.3 & Physical Hazards & & & \\
& 1.4 & Plastic extraneous matters & 5 & 1 & 6 \\
& & Extraneous matters, metals, glass, stones & 3 & 6 & 6 \\
& 1.5 & Biological Hazards & & & \\
& 1.6 & Parasites & 2 & 1 & 5 \\
& 1.7 & Salmonella SPP & 2 & 6 & 5 \\
& 1.8 & Aeromonas Hydrophila & 2 & 4 & 5 \\
& & Listeria Monocytogenes & 8 & 8 & 5
\end{tabular}

\section{Defrosting}

Washing and salting

Smoke

flavouring

\section{Chemical Hazards}

Allergens

$2 \quad 6 \quad 3$

Physical Hazards

Plastic extraneous matters

$\begin{array}{lll}5 & 1 & 3\end{array}$

$\begin{array}{lll}3 & 6 & 3\end{array}$

Extraneous matters, metals, glass, stones

Biological Hazards

Listeria Monocytogenes

$\begin{array}{lll}8 & 8 & 2\end{array}$

\section{Chemical Hazards}

Allergens

$2 \quad 6 \quad 3$

Physical Hazards

Plastic extraneous matters

$\begin{array}{lll}4 & 1 & 3\end{array}$

Extraneous matters, metals, glass, stones

$\begin{array}{lll}4 & 6 & 3\end{array}$

\section{Biological Hazards}

Listeria Monocytogenes

$\begin{array}{lll}7 & 8 & 2\end{array}$

\section{Chemical Hazards}

Benzopyrene and other polycyclic aromatic hydrocarbons

Allergens

$\begin{array}{lll}5 & 10 & 5\end{array}$

Physical Hazards

$\begin{array}{lll}2 & 6 & 3\end{array}$

Plastic extraneous matters

Extraneous matters, metals, glass, stones

$\begin{array}{lll}4 & 1 & 3\end{array}$

Biological Hazards

Listeria Monocytogenes
263 $\begin{array}{lll}9 & 8 & 2\end{array}$ 
Slicing

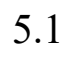

5.2

Packaging and labeling

6.1

6.2

6.3

6.4

6.5

\section{Chemical Hazards}

Allergens

$2 \quad 6 \quad 3$

Physical Hazards

$\begin{array}{llll}\text { Plastic extraneous matters } & 2 & 1 & 2\end{array}$

Extraneous matters, metals, glass, stones $\quad 2 \quad 6 \quad 2$

Biological Hazards

$\begin{array}{llll}\text { Listeria Monocytogenes } & 9 & 8 & 2\end{array}$

\section{Chemical Hazards}

Allergens

263

\section{Physical Hazards}

Plastic extraneous matters $\quad \begin{array}{lll}1 & 1 & 2\end{array}$

Extraneous matters, metals, glass, stones $\quad \begin{array}{llll}1 & 6 & 2\end{array}$

Biological Hazards

Parasites $\quad 2 \quad 1 \quad 2$

Listeria Monocytogenes $\quad \begin{array}{lll}9 & 8 & 2\end{array}$

As concerns criteria, $w_{O}$ and $w_{D}$ are set equal to 0.25 . On the other hand, $w_{s}$ is set equal to 0.5 . Afterwards, ratings of hazards against criteria are normalized and weighted by equations (1) and (2) respectively. Obtained values are reported in Table 2.

Table 2 Weighted and normalized matrix

\begin{tabular}{lccc}
\hline Hazard number & $\mathbf{O}$ & $\mathbf{S}$ & $\mathbf{D}$ \\
\hline 1.1 & 0.020097 & 0.124035 & 0.063623 \\
1.2 & 0.020097 & 0.093026 & 0.063623 \\
1.3 & 0.050242 & 0.015504 & 0.076348 \\
1.4 & 0.030145 & 0.093026 & 0.076348 \\
1.5 & 0.020097 & 0.015504 & 0.063623 \\
1.6 & 0.020097 & 0.093026 & 0.063623 \\
1.7 & 0.020097 & 0.062017 & 0.063623 \\
1.8 & 0.080387 & 0.124035 & 0.063623 \\
2.1 & 0.020097 & 0.093026 & 0.038174 \\
2.2 & 0.050242 & 0.015504 & 0.038174 \\
2.3 & 0.030145 & 0.093026 & 0.038174 \\
2.4 & 0.080387 & 0.124035 & 0.025449 \\
3.1 & 0.020097 & 0.093026 & 0.038174 \\
3.2 & 0.040193 & 0.015504 & 0.038174 \\
3.3 & 0.040193 & 0.093026 & 0.038174 \\
3.4 & 0.070338 & 0.124035 & 0.025449 \\
4.1 & 0.050242 & 0.155043 & 0.063623 \\
4.2 & 0.020097 & 0.093026 & 0.038174
\end{tabular}




\begin{tabular}{llll}
4.3 & 0.040193 & 0.015504 & 0.038174 \\
4.4 & 0.020097 & 0.093026 & 0.038174 \\
4.5 & 0.090435 & 0.124035 & 0.025449 \\
5.1 & 0.020097 & 0.093026 & 0.038174 \\
5.2 & 0.020097 & 0.015504 & 0.025449 \\
5.3 & 0.020097 & 0.093026 & 0.025449 \\
5.4 & 0.090435 & 0.124035 & 0.025449 \\
6.1 & 0.020097 & 0.093026 & 0.038174 \\
6.2 & 0.010048 & 0.015504 & 0.025449 \\
6.3 & 0.010048 & 0.093026 & 0.025449 \\
6.4 & 0.020097 & 0.015504 & 0.025449 \\
6.5 & 0.090435 & 0.124035 & 0.025449 \\
\hline
\end{tabular}

Reminding that all criteria are to be minimized, equations (3) and (4) are then used to compute the positive and negative ideal solutions (i.e. $A^{+}$and $A^{-}$respectively) related to every criterion (Table $3)$.

Table 3 Ideal solutions

\begin{tabular}{cccc}
\cline { 2 - 4 } & $\mathbf{O}$ & $\mathbf{S}$ & $\mathbf{D}$ \\
\hline $\boldsymbol{A}^{-}$ & 0.090435 & 0.155043 & 0.076348 \\
$\boldsymbol{A}^{+}$ & 0.010048 & 0.015504 & 0.025449 \\
\hline
\end{tabular}

Finally, distances between every hazard and the positive and negative ideal solutions are computed by equations (5) and (6) whereas the resulting closeness coefficients are calculated by the equation (7). The following Table 4 synthesizes the final ranking results.

Table 4 Final ranking results

\begin{tabular}{lrrr}
\hline \multicolumn{1}{c}{ Hazard number } & \multicolumn{1}{c}{$\boldsymbol{S}_{\boldsymbol{i}}^{-}$} & \multicolumn{1}{c}{$\boldsymbol{S}_{\boldsymbol{i}}^{+}$} & \multicolumn{1}{c}{$\boldsymbol{C}_{\boldsymbol{i}}$} \\
\hline 1.8 & 0.034992 & 0.134847 & 0.20603 \\
4.1 & 0.04216 & 0.150146 & 0.219232 \\
4.5 & 0.0596 & 0.135059 & 0.306178 \\
5.4 & 0.0596 & 0.135059 & 0.306178 \\
6.5 & 0.0596 & 0.135059 & 0.306178 \\
2.4 & 0.060442 & 0.12933 & 0.318496 \\
3.4 & 0.062897 & 0.124152 & 0.336261 \\
1.1 & 0.077916 & 0.115486 & 0.402871 \\
1.4 & 0.086493 & 0.09489 & 0.476852 \\
3.3 & 0.088474 & 0.084144 & 0.512541 \\
1.2 & 0.094634 & 0.086993 & 0.521034 \\
1.6 & 0.094634 & 0.086993 & 0.521034
\end{tabular}




\begin{tabular}{rrrr}
2.3 & 0.094543 & 0.081089 & 0.538301 \\
2.1 & 0.101247 & 0.079199 & 0.561092 \\
3.1 & 0.101247 & 0.079199 & 0.561092 \\
4.2 & 0.101247 & 0.079199 & 0.561092 \\
4.4 & 0.101247 & 0.079199 & 0.561092 \\
5.1 & 0.101247 & 0.079199 & 0.561092 \\
6.1 & 0.101247 & 0.079199 & 0.561092 \\
5.3 & 0.106697 & 0.07817 & 0.577156 \\
6.3 & 0.113573 & 0.077522 & 0.594329 \\
1.7 & 0.117317 & 0.061006 & 0.657892 \\
1.3 & 0.145212 & 0.064855 & 0.691266 \\
2.2 & 0.150146 & 0.04216 & 0.780768 \\
1.5 & 0.156782 & 0.039474 & 0.798863 \\
3.2 & 0.153143 & 0.032721 & 0.823953 \\
4.3 & 0.153143 & 0.032721 & 0.823953 \\
5.2 & 0.164345 & 0.010048 & 0.942381 \\
6.4 & 0.164345 & 0.010048 & 0.942381 \\
6.2 & 0.16889 & 0 & 1 \\
\hline
\end{tabular}

Therefore, the proposed approach classified the Listeria Monocytogenes, the benzopyrene and the other polycyclic aromatic hydrocarbons released during the smoke flavoring stage as the most critical hazards to the consumers' health. Moreover, the fish receiving and acceptance stage needs to be accurately monitored to reduce the presence of some hazards since the beginning of the process. As concerns the Listeria Monocytogenes, it represents the most critical hazard to the consumers' health from the fish receiving and acceptance stage to the distribution one. Actually, such bacterium causes the listeriosis, a disease particularly dangerous for pregnant women, immune-compromised patients, children and elderly. It can be present both in raw and smoked fishes, it survives to refrigerator temperatures and it particularly proliferates between $30^{\circ} \mathrm{C}$ and $38^{\circ} \mathrm{C}$. As a consequence, the process's temperature needs to be monitored during all stages, preferring a range between $10^{\circ} \mathrm{C}$ and $12^{\circ} \mathrm{C}$. Appropriate hygienic measures for personnel are to be taken as well.

In the light of the obtained results, the organization has decided to undertake the following corrective measures. 
- Further agreements with suppliers about the microbiological analyses to be performed on fillets of salmons to reduce the risk of Listeria Monocytogenes. In addition, suppliers will be also required to more accurately monitor all those hazards that could occur during the salmons' aquaculture into marine cages and cannot be visually detected at the acceptance check (e.g. heavy metals).

- Improving the hygienic measures on tools, machineries and workers to reduce external contaminations.

- Increasing the size of samples taken at the fish receiving stage and used for the visual and microbiological acceptance check.

- During all stages of the manufacturing process, performing a more systematic extraction of samples to be sent to the laboratory for the microbiological analyses.

\section{Conclusions}

Nowadays, the Hazard Analysis and Critical Control Point (HACCP) system represents the mainly way to implement the food safety risk management in food industries from the manufacturers' perspective. Among the seven principles of the HACCP plan development, the first one is the hazard analysis. The latter is defined as the systematic process of identification and evaluation of known or potential hazards associated with the food under consideration to decide which of them are to be addressed into the HACCP plan.

Apart from the prioritization of hazards required for the development of the HACCP plan, the authors believe that also the most critical production process stages to the consumers' health are to be identified. Doing that, priorities of intervention can be set. With this recognition, a semiquantitative approach based on HACCP and Technique for Order of Preference by Similarity to Ideal Solution (TOPSIS) has been proposed to prioritize production process stages on the basis of their actual contribute to the consumers' risk. Referring to a real smoked salmon manufacturing 
process, the hazard analysis has been firstly performed by the HACCP team of the involved organization. Afterwards, the TOPSIS method has been applied to rank production process stages on the basis of ratings of hazards against the three risk parameters Occurrence $(\mathrm{O})$, Severity $(\mathrm{S})$ and Detectability (D). In respect to the extant body of the literature, the present paper represents the first attempt to deal with the prioritization problem in food manufacturing environments by the TOPSIS method. The proposed approach classified the Listeria Monocytogenes, the benzopyrene and the other polycyclic aromatic hydrocarbons released during the smoke flavoring stage as the most critical hazards to the consumers' health. Moreover, the fish receiving and acceptance one needs to be accurately monitored to reduce the presence of some hazards since the beginning of the process. To the Authors' opinion, the proposed procedure provides to the company under investigation a useful tool to decide the more appropriate corrective measures to be taken to minimize the impact of the aforementioned hazards on the manufacturing process.

In practical real-life situations, human judgments are often vague and uncertain so that the elicitation of exact numerical ratings on alternatives and/or criteria can be difficult. On the other hand, experts are more likely able to express their own judgments by means of linguistic variables. With this recognition, possible future developments may concern the use of structured methods to deal with the epistemic uncertainty which naturally affects human judgments. 


\section{References}

Aiello, G, Enea, M, Galante, G and La Scalia, G. (2009) 'Clean agent selection approached by fuzzy TOPSIS decision-making method', Fire Technology, Vol. 45, pp.405 - 418.

Arvanitoyannis, IS and Varzakas, TH. (2008) 'Application of ISO 22000 and Failure Mode and Effect Analysis (FMEA) for industrial processing of salmon: A case study', Critical Reviews in Food Science and Nutrition, Vol. 48 No.5, pp.411 - 429.

Arvanitoyannis, IS and Varzakas, TH. (2009) 'Application of failure mode and effect analysis (FMEA) and cause and effect analysis in conjunction with ISO 22000 to a snails (Helix aspersa) processing plant; A case study', Critical Reviews in Food Science and Nutrition, Vol. 49 No.7, pp.607 - 625 .

Awasthi, A, Chauhan SS and Goyal, SK. (2010) 'A fuzzy multicriteria approach for evaluating environmental performance of suppliers', International Journal of Production Economics, Vol. 126, pp.370 - 378.

Azarnivand, A, and Banihabib, ME. (2017) 'A multi-level strategic group decision making for understanding and analysis of sustainable watershed planning in response to environmental perplexities', Group Decision and Negotiation, Vol. 26, No. 3, pp.629-648.

Behzadian, M, Otaghsara, K, Yazdani, M and Ignatius, J. (2012) 'A state-of the-art survey of TOPSIS applications', Expert Systems with Applications, Vol. 39, pp.13051 - 13069.

Bertolini, M, Rizzi, A and Bevilacqua, M. (2007) 'An alternative approach to HACCP system implementation', Journal of Food Engineering, Vol. 79, pp.1322 - 1328.

Bevilacqua, M and Ciarapica, FE (2018) 'Human factor risk management in the process industry: A case study', Reliability Engineering and System Safety, Vol. 169, pp.149 - 159.

Bevilacqua, M, Ciarapica, FE and Mazzuto G (2018) 'Fuzzy cognitive maps for adverse drug event risk management', Safety Science, Vol. 102, pp.194 - 210. 
Butler, F. (2008). Risk Analysis in Food Safety. Irish Microbial Risk Assessment Network, Tutorial Series Issue 1. http://www.ucd.ie/microbialrisknetwork/

Carpitella, S, Certa, A, Enea, M, Galante, GM, Izquierdo, J, La Fata, CM and Vella, F. (2017), 'Combined HACCP and TOPSIS-based approach to prioritize risks in the salmon manufacturing process: a case study' in Proceedings of the Summer School Francesco Turco, 13-15 September 2017, Palermo, Italy.

Carpitella, S, Certa, A, Izquierdo, J and La Fata, CM. (2018a) 'k-out-of-n systems: an exact formula for the stationary availability and multi-objective configuration design based on mathematical programming and TOPSIS', Journal of Computational and Applied Mathematics, Vol. 220, pp.1007- 1015.

Carpitella, S, Certa, A, Izquierdo, J and La Fata, CM. (2018b), 'A combined multi-criteria approach to support FMECA analyses: A real-world case', Reliability Engineering and System Safety, Vol. 169 , pp.394 - 402.

Carpitella, S., Certa, A., Galante, G., Izquierdo, J. and La Fata, CM. (2016), 'The FTOPSIS method to support FMECA analyses' in Proceedings - 22nd ISSAT International Conference on Reliability and Quality in Design 2016, Los Angeles, U.S.A., pp. 398 - 402.

Certa, A, Enea, M, Galante, GM and La Fata, CM. (2017a) 'ELECTRE TRI-based approach to the failure modes classification on the basis of risk parameters: An alternative to the risk priority number', Computers \& Industrial Engineering, Vol. 108, pp.100 - 110.

Certa, A, Hopps, F, Inghilleri, R and La Fata, CM. (2017b) 'A Dempster Shafer Theory-based approach to the Failure Mode, Effects and Criticality Analysis (FMECA) under epistemic uncertainty: application to the propulsion system of a fishing vessel', Reliability Engineering \& System Safety, Vol. 159, pp.69 - 79.

Certa, A., Enea, M., Galante, G. and Lupo T. (2013), 'A multi-decision makers approach to select the maintenance plan for a multi-component system', in RQD 2013: Proceeding of the 19 th ISSAT 
International Conference on Reliability and Quality in Design, Honolulu, Hawai, USA, pp. 434438.

Chang, WL, Pang, LM and Tay, KM. (2017) 'Application of self-organizing map to failure modes and effects analysis methodology, Neurocomputing, Vol.249, pp.314 - 320 .

Chen, CT. (2000) 'Extensions of the TOPSIS for group decision-making under fuzzy environment', Fuzzy Sets and System, Vol. 114 No. 1, pp.1 - 9.

Commission Regulation EC 835/2011 of the European Commission - as regards maximum levels for polycyclic aromatic hydrocarbons in foodstuffs. Official Journal of the European Union.

Commission Regulation EC No 1881/2006 of the Commission of the European Communities setting maximum levels for certain contaminants in foodstuffs. Official Journal of the European Union.

Commission Regulation EC No 2073/2005 of the Commission of the European Communities - on microbiological criteria for foodstuffs. Official Journal of the European Union.

Curcurù, G, Galante GM and La Fata, CM. (2013) 'An imprecise Fault Tree Analysis for the estimation of the Rate of OCcurrence Of Failure (ROCOF)', Journal of Loss Prevention in the Process Industries, Vol. 26, pp.1285 - 1292.

Doménech, E, Escriche, I and Martorell, S. (2007) 'Quantification of risks to consumers' health and to company's incomes due to failures in food safety', Food Control, Vol. 18, pp.1419 - 1427.

FAO/WHO (1997). Introducing the Hazard Analysis and Critical Control Point System. World Health Organisation. Document WHO/fsf/FOS/97.2, Geneva.

FAO/WHO (2005). Food Safety Risk Analysis PART I. An Overview and Framework Manual.

FAO/WHO (2006). Food safety risk analysis. A guide for national food safety authorities. World Health Organization - Food and Agriculture Organization of the United Nations, Rome.

Galante, G.M. and La Fata, C.M. (2017), 'Combined Fuzzy TOPSIS and AHP-based Methodology for the Prioritization of Maintenance Key Performance Indicators: Application to an Oil Refinery 
Plant' in ICSRS 2017: Proceedings of the $2^{\text {nd }}$ International Conference on Systems Reliabiity and Safety, Milan, Italy, pp. 337-342.

Govidan, K, Khodaverdi, R and Jafarian, A. (2013) 'A Fuzzy multi criteria approach for measuring sustainability performance of a supplier based on triple bottom line approach', Journal of Cleaner Production, Vol. 47, pp.345 - 354.

Grassi A, Gamberini, R, Mora, C and Rimini, B. (2009) 'A fuzzy multi-attribute model for risk evaluation in workplaces', Safety Science, Vol. 47, pp.707 - 716.

Gumus, AT. (2009) 'Evaluation of hazardous waste transportation firms by using a two steps fuzzyAHP and TOPSIS methodology', Expert Systems with Applications, Vol. 36, pp.4067 - 4074.

$\mathrm{Hu}, \mathrm{J}, \mathrm{Du}, \mathrm{Y}, \mathrm{Mo}, \mathrm{H}$, Wei, D and Deng, Y (2016) 'A modified weighted TOPSIS to identify influential nodes in complex networks', Physica A: Statistical Mechanics and its Applications, Vol. 444, pp.73-85.

Hwang, C.L. and Yoon, K. (1981) Multiple Attributes Decision Making Methods and Applications, Springer, Berlin Heidelberg.

Hwang, C-L, Lai, YJ and Liu, TY. (1993) 'A new approach for multiple objective decision making', Computers and Operational Research, Vol. 20, pp.889 - 899.

International Electrotechnical Commission (2006) IEC 60812:2006. Analysis techniques for system reliability - procedure for failure mode and effects analysis (FMEA). Geneve, Switzerland.

International Electrotechnical Commission (2006) IEC 61025:2006. Fault Tree Analysis (FTA). Geneva, Switzerland.

ISO 22000:2005. Technical Committee ISO/TC 34 of the International Organization for Standardization (2005). Food safety management systems - Requirements for any organization in the food chain.

Jain, P, Pasman, HJ, Waldram, S, Pistikopoulos, EN and Mannan, MS (2017, in press) 'Process Resilience Analysis Framework (PRAF): A systems approach for improved risk and safety 
management', Journal of Loss Prevention in the Process Industries, http://dx.doi.org/10.1016/j.jlp.2017.08.006.

Jędrkiewicz, R, Tsakovski, S, Lavenu, A, Namieśnik, J and Tobiszewski, M. (2018) 'Simultaneous grouping and ranking with combination of SOM and TOPSIS for selection of preferable analytical procedure for furan determination in food', Talanta, Vol. 38, pp.928 - 933

KarimiAzari, A, Mousavi, N, Mousavi, SF and Hosseini, S. (2011) 'Risk assessment model selection in construction industry', Expert System with Applications, Vol. 38, pp. 9105 - 9111.

Kumar, A and Agrawal, VP. (2009) 'Attribute based specification, comparison and selection of electroplating system using MADM approach', Expert System with applications, Vol. No 36, pp. $10815-10827$.

Kurt, L and Özilgen, S. (2013) 'Failure mode and effect analysis for dairy product manufacturing: Practical safety improvement action plan with cases from Turkey', Safety Science, Vol. 55, pp.195 206.

La Fata, CM and Lupo, T. (2017), A combined fuzzy-SEM evaluation approach to identify the key drivers of the academic library service quality in the digital technology era: An empirical study, Journal of the Association for Information Science and Technology, Vol. 68 No.10, pp.2425 2438.

La Scalia, G, Aiello, G, Rastellini, C, Micale, R and Cicalese, L. (2011) 'Multi-Criteria Decision Making support system for pancreatic islet transplantation', Expert Systems with Applications, Vol. 38, pp.3091 - 3097 .

La Scalia, G, Marra, FP, Rühl, J, Sciortino, R and Caruso, T. (2016) 'Fuzzy multi-criteria decisionmaking methodology to optimise olive agro-engineering processes based on geo-spatial technologies', International Journal of Management and Decision Making, Vol. 15 No.1, pp.1 - 15. Lima, FR, Osiro, L and Carpinetti, LCR. (2014) 'A comparison between fuzzy AHP and fuzzy TOPSIS methods to supplier selection', Applied Soft Computing, Vol. 21, pp.194 - 209. 
Liu, H-C, Liu, L and Liu, N. (2013) 'Risk evaluation approaches in failure mode and effects analysis: A literature review', Expert Systems with Applications, Vol. 40, pp.828 - 838.

Lourenzutti R and Krohling RA. (2016) 'A generalized TOPSIS method for group decision making with heterogeneous information in a dynamic environment', Information Science; Vol. 330, pp. 118.

National Advisory Committee for Microbiological Criteria for Foods. (1998) 'Hazard Analysis and Critical Control Point Principles and Application Guidelines', Journal of food protection, Vol. 61, pp.1246 - 1259 .

Oscar, T.P. (2012) 'Food Risk Analysis', in Oyarzabal O.A. and Backert S. (Ed), Microbial Food Safety: An Introduction, Springer Verlag, New York.

Oyarzabal, OA. (2015) 'Understanding the differences between hazard analysis and risk assessment.' Food Safety Magazine, http://www.foodsafetymagazine.com/enewsletter/

Ozilgen, S. (2012) 'Failure mode and effect analysis (FMEA) for confectionery manufacturing in developing countries: Turkish delight production as a case study', Ciencia e Tecnologia de Alimentos, Vol. 32 No.3, pp.505 - 514.

Regulation EC No 178/2002 of the European Parliament and of the Council - laying down the general principles and requirements of food law, establishing the European Food Safety Authority and laying down procedures in matters of food safety. Official Journal of the European Union.

Regulation EC No 852/2004 of the European Parliament and of the Council - on the hygiene of foodstuffs. Official Journal of the European Union.

Rubayet, K and Karmaker, CL (2016) 'Machine selection by AHP and TOPSIS methods', American Journal of Industrial Engineering, Vol. 4, No. 1, pp.7 - 13.

Scipioni, A, Saccarola, G, Centazzo, A and Arena, F (2002) 'FMEA methodology design, implementation and integration with HACCP system in a food company', Food Control, Vol. 13, pp.495 - 501 . 
Serra, JA, Domenech, E, Escrichea, I and Martorell S. (1999) 'Risk assessment and critical control points from the production perspective', International Journal of Food Microbiology, Vol. 46, pp.9 $-26$.

Shih, HS. (2008) 'Incremental analysis for MCDM with an application to group TOPSIS', European Journal of Operational Research, Vol. 186, pp. 720-734.

Sutrisno, A, Gunawan, I, Khorshidi, HA and Tangkuman, S (2015) 'A new modified FMEA model for ranking the risk of maintenance waste considering hierarchy of root causes and effects', International Journal of Quality Engineering and Technology, Vol. 5 No.3-4, pp. 217 - 237.

Taylan, O, Zytoon, MA, Morfeq, A, Al-Hmouz, R and Herrera-Viedma, E. (2017) 'Workplace assessment by fuzzy decision tree and TOPSIS methodologies to manage the occupational safety and health performance', Journal of Intelligent and Fuzzy Systems, Vol. 33, No. 2, pp.1209 - 1224.

Trafialek, J and Kolanowski, W. (2014) 'Application of Failure Mode and Effect Analysis (FMEA) for audit of HACCP system', Food Control, Vol. 44, pp.35 - 44.

Varzakas, TH and Arvanitoyannis, IS. (2007) 'Application of Failure Mode and Effect Analysis (FMEA), cause and effect analysis, and Pareto diagram in conjunction with HACCP to a corn curl manufacturing plant', Critical Reviews in Food Science and Nutrition, Vol. 47 No.4, pp.363 - 387. Varzakas, TH. (2011) 'Application of ISO 22000, failure mode, and effect analysis (FMEA) cause and effect diagrams and Pareto in conjunction with HACCP and risk assessment for processing of pastry products' Critical Reviews in Food Science and Nutrition, Vol. 51 No.8, pp.762 - 782.

Wang X, Yang F, Wei H and Zhang, L. (2015) 'A new ranking method based on TOPSIS and possibility theory for multi-attribute decision making problem. 'Optik - International Journal for Light and Electron Optics', Vol. 126 No 24, pp. 4852 - 4860.

Xiaochuan, W and Qiang, L. (2015) 'Formulation and implementation of meat product HACCP plan based on FMEA', Advance Journal of Food Science and Technology, Vol. 7 No.8, pp.579 583. 
Zeydan, M, Colpan, C and Cobanoğlu, C. (2011) 'A combined methodology for supplier selection and performance evaluation', Expert Systems with Applications, Vol. 38, pp.2741 - 2751.

Zhang, S, Sun, B, Yan, L and Wang, C (2013) 'Risk identification on hydropower project using the IAHP and extension of TOPSIS methods under interval-valued fuzzy environment', Natural Hazard, Vol. 65, No 1, pp.359 - 373. 